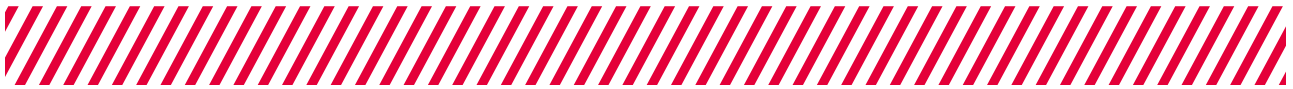

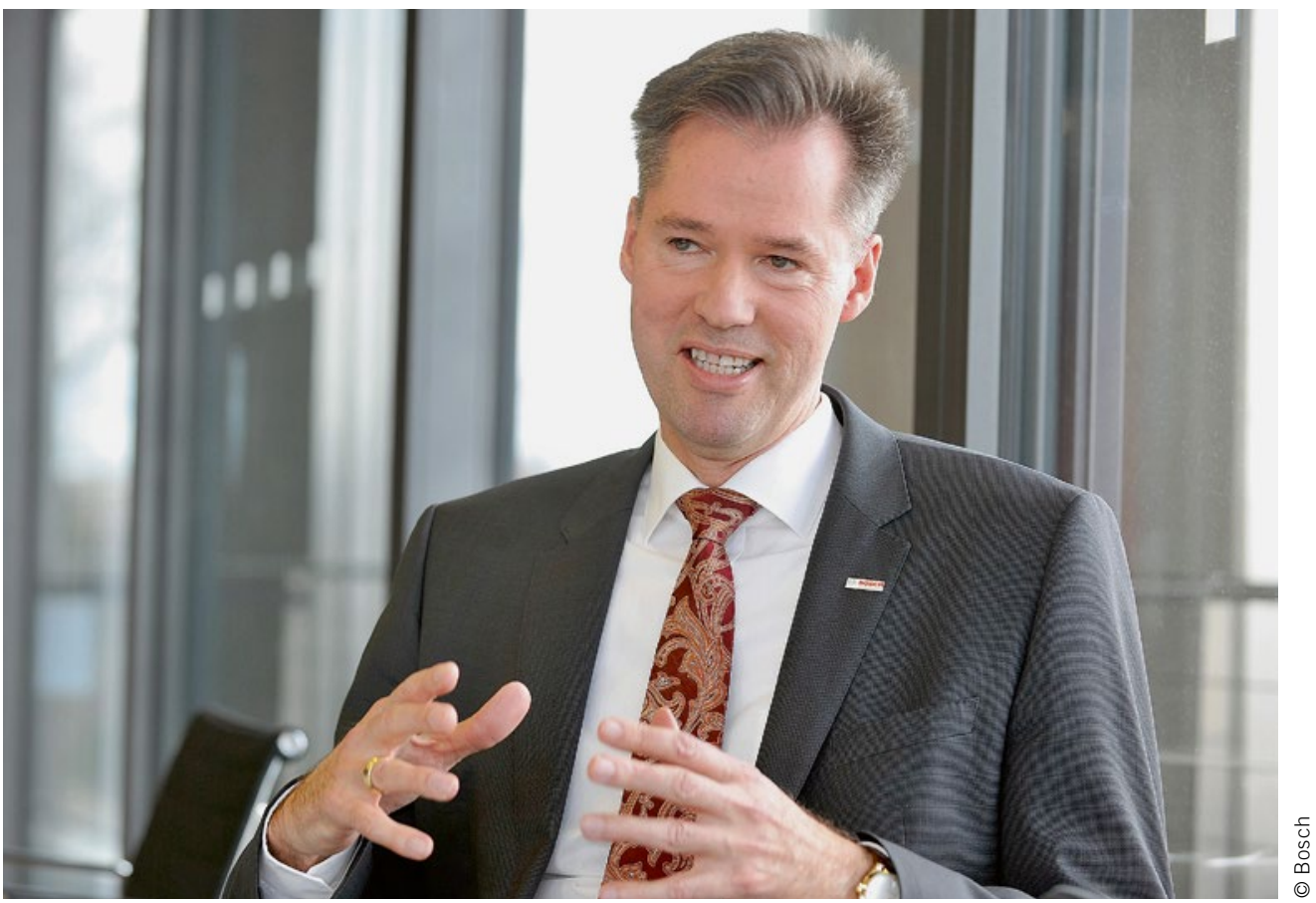

Dr.-Ing. Markus Heyn

Member of the Board of Management of Robert Bosch $\mathrm{GmbH}$ with Corporate Responsibility for Automotive Original Equipment Sales and Marketing and Sales, as well as the company's Automotive Aftermarket division and the Etas $\mathrm{GmbH}$ and Bosch Engineering $\mathrm{GmbH}$ subsidiaries; Member of the ATZ Advisory Board

\section{From Truck Driver to Networked Cargo Pilot}

Commercial vehicles have always functioned as platforms for new technologies. New systems that cut costs, reduce downtimes and increase efficiency are adopted quickly throughout the industry. This year's IAA Commercial Vehicles will give an impressive demonstration of why networked and autonomous trucks will soon become something that we take for granted. The aim of these developments is to improve efficiency and safety, and they will also lead to major growth opportunities for suppliers. For this reason, Bosch established a separate division in early 2016 to coordinate all its existing commercial vehicle and off-road activities. Our intention is to become an even more effective partner for OEMs by providing them with innovative ideas and comprehensive system solutions.

The fact that ESP, lane departure warning systems and emergency braking assistance systems have become standard features in commercial vehicles represents a major step towards increasing road safety. The emergency braking assistance systems alone could reduce the number of accidents involving commercial vehicles by around $70 \%$. In addition, these functions will form the basis for autonomous driving. In future, trucks' computers will be able to park the vehicles automatically in the haulage companies' yards.

Trucks are already operating with partial autonomy on the motorway. The long-term goal is platooning, which involves several vehicles travelling in convoy. The networked trucks will receive their braking and steering information from the leading vehicle. The short distances between them will reduce wind resistance and therefore also fuel consumption. In addition, the drivers in the trucks following the leader will be able to take a break. The connectivity technology also opens up many other opportunities for providing a variety of services. For example, in future Bosch Secure Truck Parking will help drivers to find a place to park in the evening. The driver will be able to see all the free parking spaces online and book and pay for one with just a few clicks. The Bosch IoT Cloud in the background forms the technical basis for this service.

New system solutions of this kind will transform truck drivers into networked cargo pilots. It is not only the truck that will be constantly online, but also the goods on board. Transport containers with integrated sensors will be able to report regularly on the temperature of the cargo and whether it has been dropped or thrown, for example. Smartphones and tablets will help with managing the data and the orders and with logging the journey. Bosch will be presenting its show truck at the IAA Commercial Vehicles and this will give an idea of what truck cabs could look like in future. The focus is on automation and connectivity, together with the necessary control and display systems and logistics applications. The truck is equipped with a digital rear-view mirror which has a video camera. This new system is ready for use in production vehicles. The mirror significantly reduces the size of the driver's blind spot and leads to lower wind resistance, which in turn helps to improve efficiency. 